\title{
MENSAGEM DO DIRECTOR DA FACULDADE DE DIREITO DE SÃO PAULO AO DIRECTOR DA FACOLTÃ DI GIURISPRUDENZA DELLA REGGIA UNIVESITA DI ROMA
}

Quando do embarque da Embaixada Academica em visita á Italia, em fevereiro do corrente anno, teve o professor Francisco Morato, director da Faculdade de Direito da Universidade de S. Paulo, ensejo de endereçar ao professor Gustavo Del Vecchio, director da Facoltà di Giurisprudenza da R. Universidade de Roma, a mensagem abaixo transcripta. Foi portador da mensagem o professor Jorge Americano, lente da Faculdade de Direito, presidente da Embaixada.

São Paulo, 8 de fevereiro de 1938.

Excellentissimo Senhor Professor:

E com o mais vivo prazer que tenho a honra de apresentar a Vossa Excellencia o professor Jorge Americano, cathedratico de Direito Civil de nossa Faculdade de Direito, que segue acompanhado de um grupo de alumnos, em embaixada especialmente designada para levar a Vossa Excellencia, á Facoltà di Giurisprudenza della Regia Università di Roma e aos seus illustrissimos Professores a expressão de nossas homenagens, de saudações de nossa Escola e dos votos de solidariedade de seus Professores e mocidade academica.

Esperamos que Vossa Excellencia acolherá com agrado nossa visita, a qual servirá para ainda mais estreitar, no mundo das lettras e dos affectos, o commercio fraternal e fecundo entre os academicos brasileiros de $\mathrm{S}$. Paulo e os italianos de Roma. E com ufania que aqui mantemos e vibramos para o futuro as vozes, virtualidades e esperanças de nossa raça, de coração e pensamento 
voltados para os confrades que as defendem e representam no berço glorioso e fulgurante da latinidade.

Acceitae, Excellentissimo Senhor, a segurança de nossos melhores augurios e sympathia.
Ao Egregio e Excellentissimo Professor Gustavo Del Vecchio, Direttore della Facoltà di Giurisprudenza della Regia Università di Roma.

\section{(a) Francisco Morato.}

\section{PREMIO "INSTITUTO DOS ADVOGADOS DE S. PAULO"}

O Instituto dos Advogados de São Paulo instituiu, em fins do anno passado, um premio para o estudante que mais se distinguir no eurso da Faculdade de Direito. A deliberação approvada nesse sentido foi a seguinte:

\section{“PREMIO INSTITUTO DOS ADVOGADOS DE SÃO PAULO}

Art. $10^{\circ}$ - Fica instituido sob o patrocinio do Instituto dos Advogados de São Paulo um premio denominado "PREMIO INSTITUTO DOS ADVOGADOS DE SÃO PAULO" a conferir-se annualmente ao melhor alumno que concluir o curso da Faculdade de Direito da Universidade de S. Paulo.

Art. 2. ${ }^{\circ}$ - Esse premio será constituido de doações de obras jurídicas, feitas por advogados membros do Instituto ou não, por quaesquer outras pessôas.

$\S$ único - As obras doadas serão carimbadas com as dizeres - "Premio Instituto dos Advogados de São Paulo"

Art. 3.0 - Para determinação de qual seja o melhor alumno a mesa do Instituto obterá na Secretaria da Faculdade o nome do alumno que obteve a maior média no seu curso, computada esta pela somma das notas obtidas tanto em exames parciaes como finaes a que se houver submettido, valendo zero os exames parciaes a que houver faltado, e 